

\section{REVISTA \\ TEORÍA Y PRÁCTICA \\ DE LA \\ ARQUEOLOGÍA HISTÓRICA LATINOAMERICANA}

ISSN: 2250-866X (impreso) | ISSN: 2591-2801 (en línea)

AÑO VIII, VOLUMEN 9, PRIMAVERA DE 2019

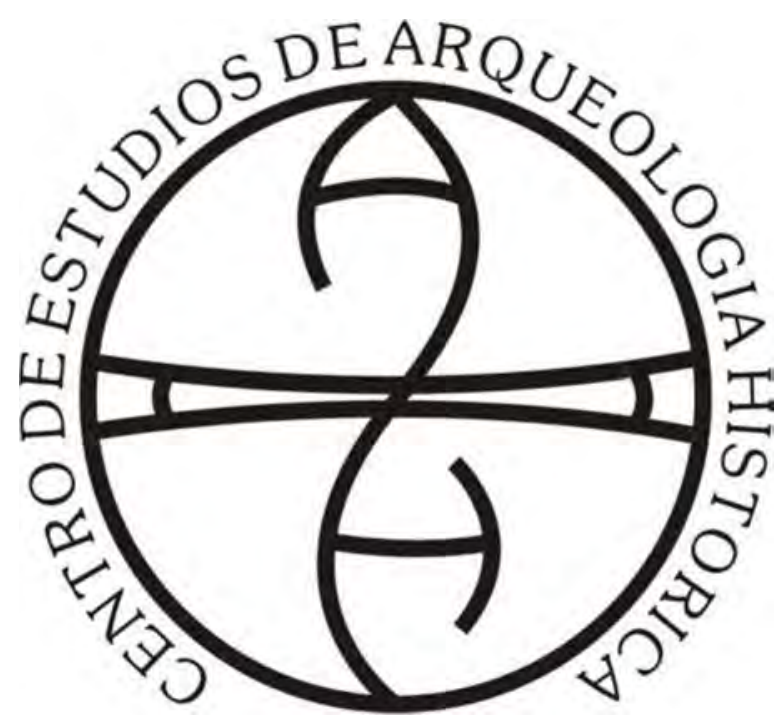

CENTRO de Estudios de ARqueOlOGía HistóricA

FACULTAD DE HUMANIDADES Y ARTES | UNIVERSIDAD NACIONAL DE ROSARIO 
(Universidad Nacional de Rosario, Universidad Nacional de Río Cuarto,

Universidad Nacional de San Juan, Universidad de la República, Universidad Nacional de Trujillo)

\author{
AUTORIDADES DE LA UNIVERSIDAD NACIONAL DE ROSARIO \\ RECTOR: Lic. Franco Bartolacci \\ VICE-RECTOR: Od. Darío Macía \\ SECRETARIO GENERAL: Prof. José Goity \\ SECRETARIA ACADÉMICO Y DE APRENDIZAJE: Dr. Marcelo Vedrovnik \\ SECRETARÍA DE CIENCIA TECNOLOGÍA E INNOVACIÓN \\ PARA EL DESARROLLO: Ing. Guillermo Montero.
}

\author{
AUTORIDADES DE LA FACULTAD DE HUMANIDADES Y ARTES \\ DECANO: Prof. Alejandro Vila \\ VICEDECANA: Prof. Marta Varela \\ SECRETARIA ACADÉMICA: Dra. Marcela Coria
}

\author{
AUTORIDADES DEL CENTRO DE ARQUEOLOGÍA HISTÓRICA \\ DIRECTORA: Dra. Ana Rocchietti \\ SECRETARIA: Prof. Nélida de Grandis \\ PROSECRETARIA: Lic. Marianela Bizcaldi
}

DIRECTORAS - EDITORAS:

Dra. Ana Rocchietti y Prof. Nélida De Grandis

SECRETARIA DE EDICIÓN: Dra. Irene Dosztal

Este número es co-edición de las ponencias

del VIII Congreso Nacional de Arqueología Histórica (2018) entre:

Centro de Estudios en Arqueología Histórica: Directora Ana Rocchietti

Centro de Estudios en Arqueología Regional: Director Fernando Oliva

Centro de Estudios en Arqueología Subacuática: Directora Mónica Valentini

Departamento de Arqueología, Escuela de Antropología: Director Fernando Oliva
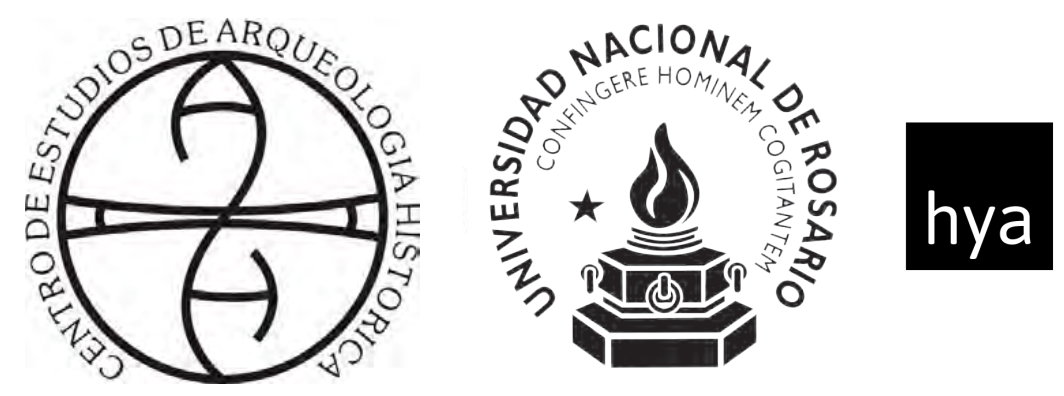

Facultad de Humanidades

y Artes_UNR
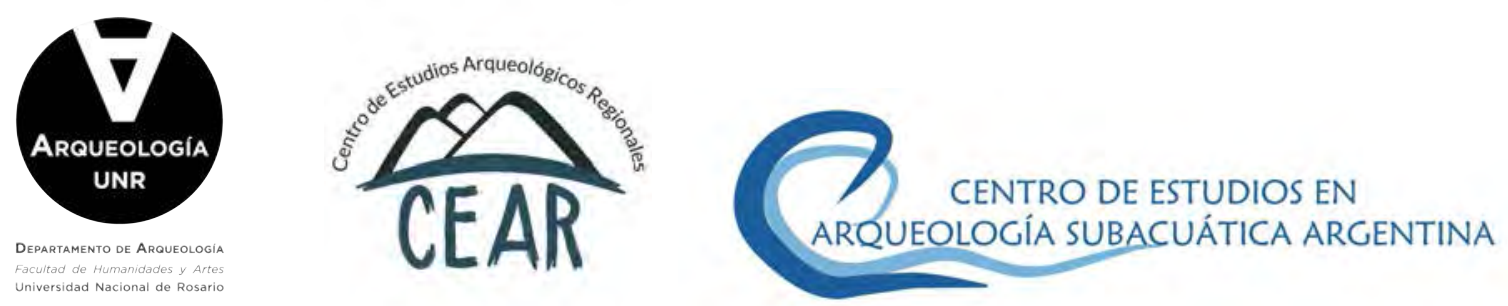
Comité Permanente de los Congresos Nacionales de Arqueología Histórica

Dr. Daniel Schávelzon (Universidad Nacional de

Buenos Aires)

Prof. María Teresa Carrara (Universidad Nacional de Rosario)

Prof. Carlos Baldassarre (Museo Municipal de Río

Grande, Tierra del Fuego) in memoriam

Dr. Mariano Ramos (Universidad Nacional de Luján, CONICET)

Dr. Horacio Chiavazza (Universidad Nacional de Cuyo)

Dra. Ana María Rocchietti (Universidad Nacional de

Rosario, Universidad Nacional de Río Cuarto)

Lic. Facundo Gómez Romero (Universidad Autónoma

de Barcelona)

\section{Comité Científico}

Dra. Tânia Andrade Lima (Universidade Federal do Rio de Janeiro)

Prof. Réginald Auger (CELAT/Département des

Sciences Historiques, Université Laval, Canadá)

Dr. Roberto Bárcena (Universidad Nacional de Cuyo, CONICET)

Dra. Marta Bonaudo (Universidad Nacional de Rosario, CONICET)

Dr. Leonel Cabrera (Universidad de la República, Uruguay)

Dr. Luis María Calvo (Universidad Católica de Santa

$\mathrm{Fe})$

Prof. Juan Castañeda Murga (Universidad Nacional de

Trujillo, Perú)

Dr. Carlos Ceruti (Museo de Ciencias Naturales y

Antropología "Prof. Antonio Serrano”. Paraná)

Dr. Horacio Chiavazza (Universidad Nacional de Cuyo)

Dra. Silvia Cornero (Universidad Nacional de Rosario)

Prof. Pedro Paulo Funari (Universidade Estadual de

Campinas, Brasil)

Lic. Jorge A. Gamboa Velásquez (Universidad Nacional

Santiago Antuñez de Mayolo, Perú)

Dr. Eduardo Alejandro García (Universidad Nacional de

San Juan, CONICET)

Prof. Nélida De Grandis (Universidad Nacional de

Rosario)

Dr. Juan Bautista Leoni (Universidad Nacional de

Rosario, CONICET)

Dra. Amancay Martínez (Universidad Nacional de San

Luis)

Dra. Catalina Teresa Michieli (Universidad Nacional de

San Juan, CONICET)

Lic. Fernando Oliva (Universidad Nacional de Rosario)
Ing. Adrián Pifferetti (Universidad Tecnológica Nacional Regional Rosario)

Dr. Mariano Ramos (Universidad Nacional de Luján, CONICET)

Dra. Ana María Rocchietti (Universidad Nacional de Rosario)

Dr. Daniel Schávelzon, (Universidad Nacional de Buenos Aires, CONICET)

Dra. Carlota Sempé (Universidad Nacional de La Plata)

Dr. Mario Silveira (Universidad Nacional de Buenos

Aires)

Dra. Silvia Simonassi (Universidad Nacional de Rosario)

Dra. Alicia Tapia (Universidad Nacional de Buenos Aires, Universidad Nacional de Luján)

Lic. Mónica P. Valentini (Universidad Nacional de Rosario)

Agrim. Benito Vicioso (Universidad Nacional de Rosario)

\section{Evaluaron este volumen}

Roberto Bárcena, María Teresa Boschin, Leonel Cabrera, Ulises Camino, María Rosa Carbonari, Carlos Ceruti, Horacio Chiavazza, Nicolás Ciarlo, Silvia Cornero, Eduardo Crivelli, Javier García Cano, Martín Gentinetta, María Laura Gili, Carlos Landa, Matilde Lanza, Melina Malandrino, Sebastián Pastor, Victoria Pedrotta, Josefina Piana, Mercedes Podestá, Mariano Ramos, Daniel Schavelzon, Diana Tamburini, Mónica Therrien, Mónica Valentini y María Teresa Boschin

\section{Diseño y diagramación}

Eugenia Reboiro

(eugenia.reboiro@gmail.com)

\section{Curadoría}

Ana Rocchietti e Irene Dosztal

Foto de tapa: Material arqueológico, del texto de Tapia et al.

\section{Propietario responsable:}

Facultad de Humanidades y Artes, Universidad Nacional de Rosario Centro de Estudios de Arqueología Histórica

Entre Ríos 758. Rosario, provincia de Santa

Fe (2000). Argentina.

Telf.: +54 (0341) 4802670

E-mail: ceahunr@gmail.com

Decreto Ley 6422/57 de Publicaciones

Periódicas 


\section{Índice}

Editorial

El origen del patrimonio histórico y su conservación integral en la contemporaneidad.

Yanina Aguilar

Prospección de basurales históricos de la ciudad de Rosario.

Soccorso Volpe y Gustavo Fernetti

Desconstrucción de un paisaje urbano. El Montevideo del extramuros colonial, aportes de la arqueología a su identidad actual. Ana Gamas

La Calota de Ameghino: reconsiderando un viejo tema desde la arqueología histórica.

Daniel Schávelzon

Análisis zooarqueológico de los restos hallados en una estructura sanitaria vinculada a momentos tempranos del actual barrio de Belgrano .71 Mario Silveira, Horacio Padula, Ricardo Orsini y Eva Bernat

La medida del tiempo: el reloj solar jesuita de La Cruz, provincia de Corrientes.

Fernando Oliva y María Cecilia Panizza

Sitio La Quinta: arqueología rural de campos serranos.

Flavio Ribero

Si no hay tabaco que no se note. Prácticas fumatorias en el fortin La Perra (1883-1885), La Pampa.

Alicia Tapia, Virginia Pineau y Melisa Ayelén Auge

El uso del tabaco y las pipas de caolin (clay pipes) en la frontera sur y oeste de la provincia de Buenos Aires en el siglo XIX.. .127

María del Carmen Langiano y Julio Fabián Merlo 
Patrimonio natural, urbano y arquitectónico de la costa en Mar del Plata. Federico Negroni

Huellas urbanas.

Ezequiel Serrot

Paisaje y patrimonio. La industria taninera en el siglo XX.

Provincia de Santa Fe.

Cristina Pasquali, Paola Milicic y Lara Ferré

Los desafíos de las arqueologías históricas latinoamericanas.

Andrés Zarankin

Sellos entre escombrales. Las lozas en el registro urbano

del Área Fundacional de Mendoza (siglo XIX y principios del siglo XX)

Lorena Puebla y Horacio Chiavazza

Evolución edilicia de la Plaza de Mayo de la Ciudad

de Buenos Aires (1580-1853).

Nicolás Ferrino

Gestión patrimonial en el rescate arqueológico y futuro Museo de Sitio

en Moreno 550, Ciudad Autónoma de Buenos Aires, Argentina.

María Eva Bernat, Ricardo Orsini, Horacio Padula y Mario Silvera 


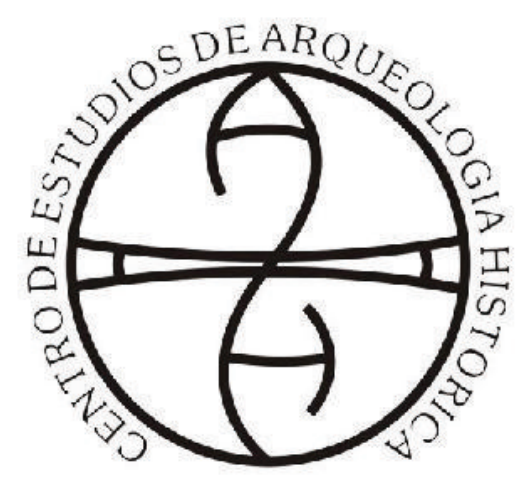

Centro de Estudios de Arqueología Histórica

Universidad Nacional de Rosario
Teoría y Práctica de la Arqueología Histórica

Latinoamericana | Año VIII. Vol. 9 | 2019

Revista del Centro de Estudios de Arqueología

Histórica, Facultad de Humanidades y Artes,

Universidad Nacional de Rosario

https://teoriaypracticaah.unr.edu.ar/index.php/index

ceahunr@gmail.com

ISSN en línea: 2591-2801

ISSN versión impresa: 2250-866X

\title{
GESTIÓN PATRIMONIAL EN EL RESCATE ARQUEOLÓGICO y futuro Museo de Sitio en Moreno 550, Ciudad Autónoma de Buenos Aires, Argentina
}

\author{
María Eva Bernat, Ricardo Orsini, Horacio Padula y Mario Silvera*
}

\begin{abstract}
Resumen
Un trabajo arqueológico conlleva no solo acciones que tienen que ver con las intervenciones "in situ" sobre todas aquellas líneas aportadas por otras disciplinas que colaboran con todo el proceso de trabajo de búsqueda de fuentes, análisis de materiales e inferencias sobre el registro recuperado; la disciplina también se ve inmersa en una serie de requerimientos y ajustes normativos que muchas veces no son reconocidas a la hora de forjar un informe de intervención.

El sitio arqueológico Moreno 550, resulta un caso paradigmático en el cual lo normativo y lo jurídico tuvieron una mayor relevancia por sobre los trabajos de campo, y esta publicación persigue desarrollar las diferentes acciones abordadas por un organismo público tendiente a preservar el patrimonio arqueológico en el sitio, proceso en el cual se suscitó una parcial destrucción de una gran cisterna, que implicó la judicialización del caso, y un consiguiente acuerdo entre las partes cuyos resultados podrán ser apreciados por todo visitante interesado en el Patrimonio de la ciudad.
\end{abstract}

Palabras clave: Emprendimiento urbano - Cisterna - Rescate arqueológico - Museo de sitio - Ley 25.743

\begin{abstract}
An archaeological work involves not only actions that have to do with the interventions "in situ" on all those lines contributed by other disciplines that collaborate with the whole work process of search of sources, analysis of materials and inferences about the recovered record; The discipline is also immersed in a series of regulatory requirements and adjustments that are often not recognized when it comes to forging an intervention report.

The archaeological site of Moreno 550, is a paradigmatic case in which the normative and the legal had a

* Centro de Interpretación de Arqueología y Paleontología de la Dirección General de Patrimonio, Museos y Casco Histórico (G.C.B.A.) orsiniricardo@yahoo.com.ar; horaciopadula@gmail.com; mbernat@buenosaires.gob.ar; mariojsilveira@gmail. com
\end{abstract}


greater relevance than field work, and this publication aims to develop the different actions addressed by a public body tending to preserve the archaeological heritage in the site, process in which a partial destruction of a large tank was caused, which involved the prosecution of the case, and a subsequent agreement between the parties whose results may be appreciated by any visitor interested in the city's heritage. Keywords: Urban Entrepreneurship -water tank - Archaeological Rescue - Site Museum - Law 25.743

\section{Introducción}

\section{Marco Legal}

Desde el año 2003 en que fue sancionada la ley № 25743 cuyo objeto es “la preservación, protección y tutela del Patrimonio Arqueológico y Paleontológico como parte integrante del Patrimonio Cultural de la Nación y el aprovechamiento científico y cultural del mismo", en su primer artículo define de manera precisa la facultad fundamental. Un órgano de aplicación debe, en el marco geográfico de su competencia, bregar por la preservación de su patrimonio arqueológico y paleontológico, y tomar todas aquellas medidas tendientes a lograrlo.

El Patrimonio cultural es el conjunto de bienes muebles e inmuebles, cualquiera sea su régimen jurídico y titularidad, que en sus aspectos tangibles e intangibles, materiales y simbólicos, y que por su significación intrínseca y/o convencionalmente atribuida, definen la identidad y la memoria colectiva de sus habitantes. (Artículo $2^{\circ}$ Ley 1.227)

En el ámbito de la ciudad, y de acuerdo al Decreto N² 2.423 (B.O Nº 2106 del 11 de enero de 2005) establece que la actual Dirección General de Patrimonio, Museos y Casco Histórico (DGPMyCH), es la autoridad de aplicación en todo lo vinculado con el régimen establecido por la ley 25.743 en este distrito, y asigna a esta Dirección General la de instrumentar las medidas necesarias para la puesta en marcha, operatividad y funcionamiento del régimen (Disposición $\mathrm{N}^{\circ} 2$ Boletín Oficial $\mathrm{N}^{\circ} 2.377$ del 2 de febrero de 2006).

Es en este marco de competencia, que el CIAP (Centro de InterpretaciónArqueológico y Paleontológico) emprende diferentes acciones dirigidas a salvaguardar todo tipo de registro arqueológico y paleontológico en el distrito. La ciudad de Buenos Aires, es portadora de un rico patrimonio en materia arqueológica, y en ella, el Casco Histórico merece una particular atención por concentrar un alto potencial en la materia.

De esta manera, este órgano de aplicación cumple trabajos de supervisión en diferentes emprendimientos urbanos tanto públicos como privados poniéndolos en conocimiento a través de la entrega de una cédula de notificación y copia adjunta de la ley 25.743 en instancias tempranas de las obras, particularmente resaltando el Art $\mathrm{N}^{\circ} 13$ de la misma en el cual queda adecuadamente establecido que

Toda persona física o jurídica que practicase excavaciones con el objeto de efectuar trabajos de construcción, agrícolas, industriales u otros de índole semejante, está obligado a denunciar al organismo competente el descubrimiento del yacimiento y de cualquier objeto arqueológico o resto paleontológico que se encontrare en las excavaciones, siendo responsable de su conservación hasta que el organismo competente tome intervención y se haga cargo de los mismos. (Ley 25.743, Artículo $\mathrm{N}^{\circ} 13$ ) 
Por otro lado, la realización de visitas periódicas tiene como objetivo diagnosticar el hallazgo de estructuras arqueológicaso la presencia de objetos y restos que hubieran requerido ser denunciados ante el órgano de aplicación.

\section{Relevancia histórica del lote}

El sitio Moreno 550, fue desde los primeros años de la década de 1970, amplia playa de estacionamiento, la cual ocupó el lote donde se levantó un edificio residencial a lo largo del siglo XX, incluidas viviendas de inquilinato, aunque el foco de interés residió en lo que pudo haber existido a menos un siglo antes.

Las fuentes de consulta en materia cartográfica, fotográfica, arquitectónica, censal, por ejemplo, constituyen parte del aspecto multidisciplinario en que la arqueología se ve envuelta a la hora de estructurar un proyecto de investigación.

El lote ubicado en la calle Moreno 550 de esta ciudad, no solo es significativo por encuadrarse dentro del denominado "Casco Histórico", sino además por su situación estratégica dentro del marco geográfico desde la distribución de suertes por parte de Juan de Garay en los días de la fundación en 1580, quien le otorgó el solar a Antonio Ermud y Alonso Gómez (Informe DGPMyCH, 2018). El sitio se ubica a 200 metros del Cabildo porteño y la Plaza de Mayo, y enfrente de la reconocida Manzana de las Luces, epicentro de la educación y la cultura de la ciudad, y donde funcionó la primera Legislatura.

En 1764, un plano confeccionado por Jaques Nicolás Bellín, permite apreciar que en el solar se encuentra la "casa del obispo". Posteriormente, la propiedad pasaría a manos del comerciante francés Felipe Filiberto de Arguibel de Larregui, quien arribara a Buenos Aires en 1753, y se asentara allí desde 1778 con su esposa y 9 hijos (Ravignani, 1919) (Figura 1).

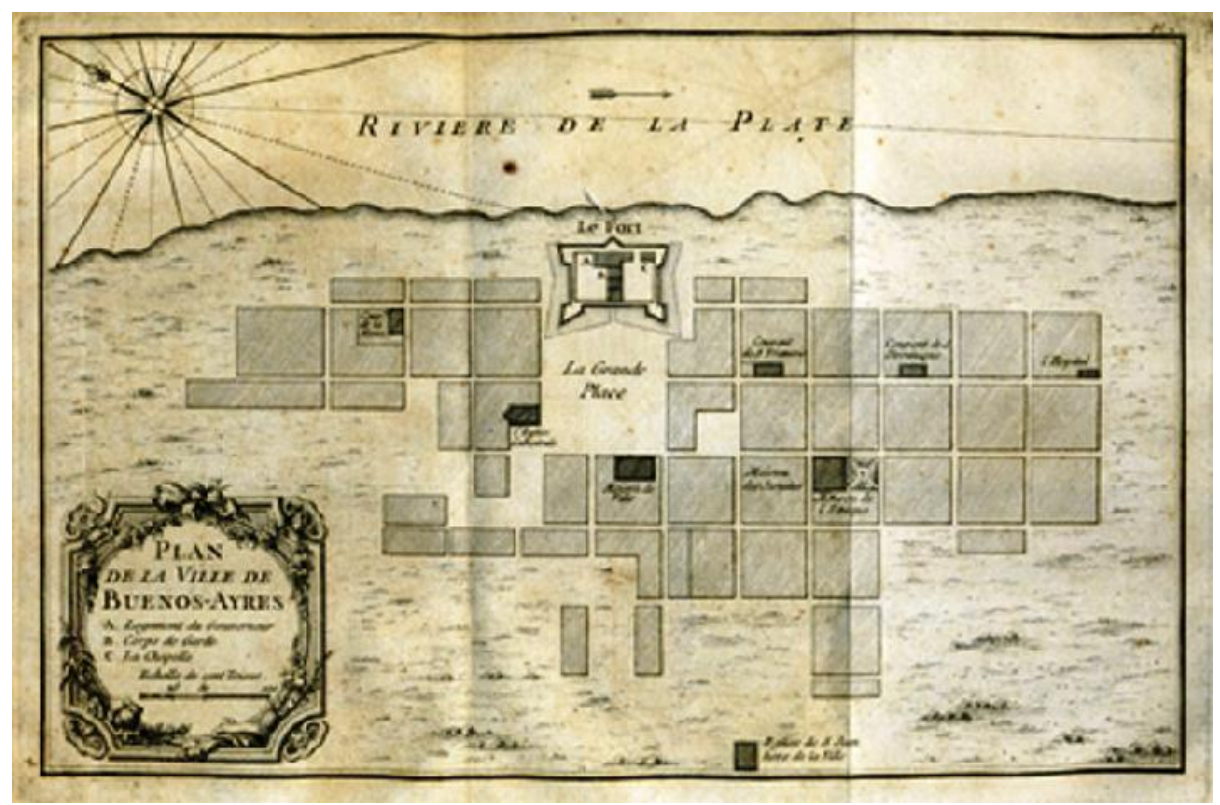

Figura 1. Plano de Buenos Aires de la segunda mitad del siglo XVIII en momentos en que en el lote de Moreno y Bolívar se encontraba la "Casa del Obispo” Grabado de Bellim, Francia. Colección Museo del Bicentenario. 
Será la hija mayor de Arguibel, Teodora Josefa, casada con el comerciante Juan Ignacio de Ezcurra Ayerra, de quienes nacen 9 hijos, una de ellas llamada María Encarnación Josefa, quien en 1813 contraerá enlace con el futuro gobernador de Buenos Aires, Juan Manuel de Rosas, quien adquiere la propiedad en 1837 (Seró Mantero 2000) (Figura 2).

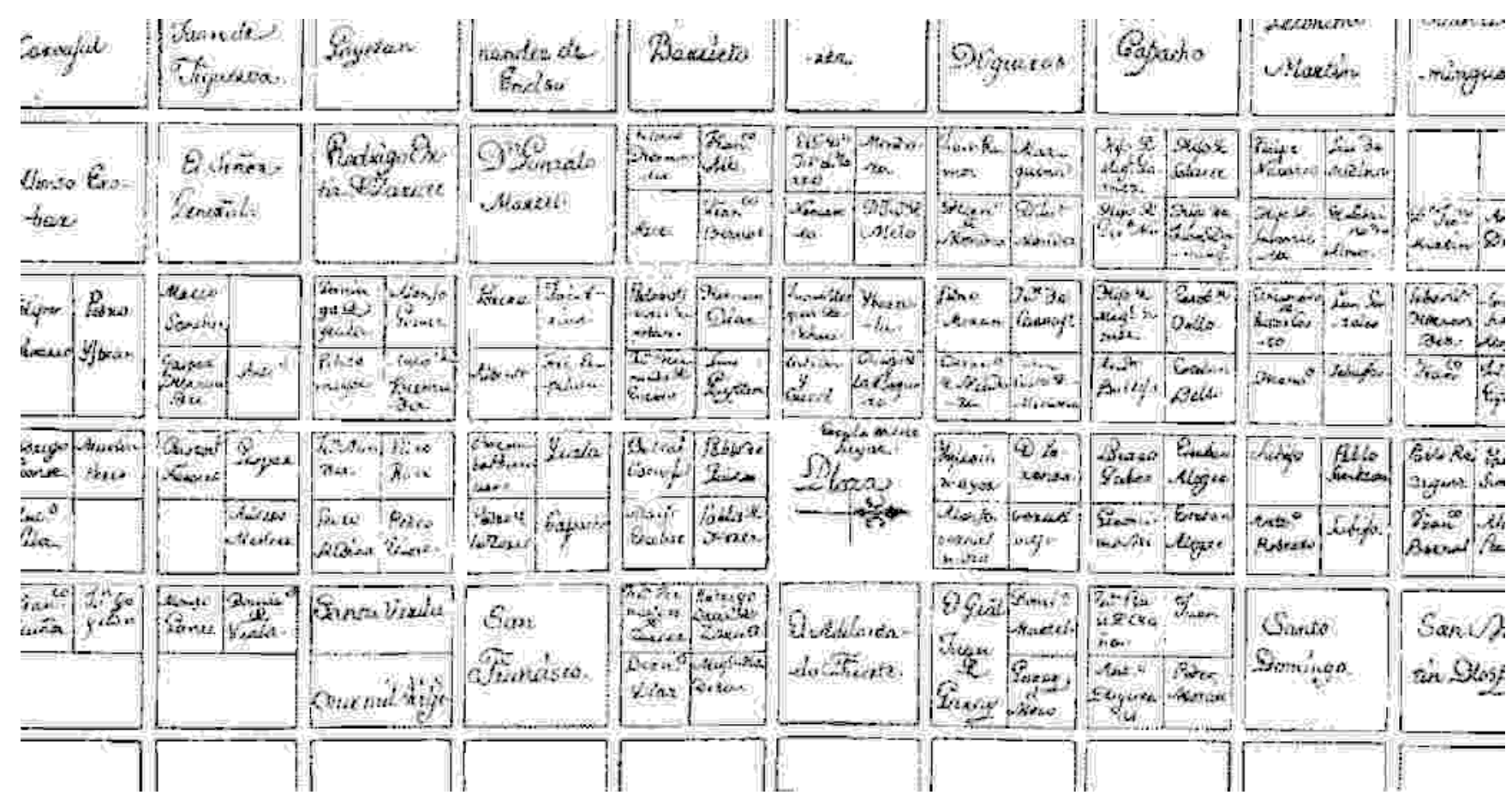

Figura 2. Distribución de solares por parte de Juan de Garay. El solar en estudio es asignado a Antonio Ermud y Alonso Gómez. Plano de la ciudad de la Santísima Trinidad y el puerto de Santa María del Buen Ayre, fundados por Don Juan de Garay en 1580 en el que se aprecia la distribución de solares por parte de Juan de Garay. El solar en estudio es asignado a Antonio Ermud y Alonso Gómez.

Original: Juan de Garay. Reproducción: desconocido - Archivo General de la Nación Argentina

Catastralmente, el lote se ubica en la Sección 02, manzana 032, parcela 008, conformando lo que se conoce como APH1 (Área de protección Histórica $\mathrm{N}^{\circ}$ 1), aunque al no estar edificada, no se encuentra alcanzada por ningún tipo de protección estructural (Informe DGPMyCH, 2018).

Ediliciamente, allí desde fines del siglo XVIII hasta principios del siglo XX, pudieron apreciarse en un lote aún mayor al que estamos siguiendo, la casona de la familia Ezcurra, la Casa de Gobierno de la Provincia, uso que siguiera aún caído el "restaurador de las leyes", dado que hasta los días de Dardo Rocha, el edificio siguió cumpliendo esa función. Posteriormente, se instaló allí la corte Suprema de Justicia, y hasta su demolición, el edificio de Correo y Telégrafos tuvo su cede en la antigua casona (Faivre 2018).

Tras la batalla de Caseros, otro sector de la propiedad fue ocupada por la Escuela Modelo, la cual comenzó a funcionar en 1857 en las actuales numeraciones Perú 302, Moreno 568 y Moreno 576 
Originariamente, la casona ocupaba gran parte de la calle Bolívar desde la esquina de Moreno, hasta la casa del obispo, y por otro lado se extendía hasta la actual calle Perú. Fue en este predio en el que vivieron Encarnación Ezcurra con Juan Manuel de Rosas desde 1830 hasta 1838 en que fallece la primera. Durante los años de su gestión, la residencia oficial en el antiguo fuerte conocido como palacio de los Gobernadores, se encontraba en claro deterioro, por lo cual y hasta que el caserón en Palermo estuviera apto para su ocupación, Rosas se instaló en el edificio de sus suegros. Fue por esta razón, que luego de su caída en 1852 en Caseros, el caserón tras varios años de litigios legales, seguirá siendo ocupada como sede gubernamental de la Provincia, siendo Vicente López y Planes el primero en utilizarla con tal finalidad (Informe DGPMyCH, 2018).

Por otro lado, un sector sobre la calle Moreno en dirección a Perú, fue ocupado desde 1858 por una escuela construida por Sarmiento conocida como "Catedral al Sud"

Finalmente, en 1885 fue adquirida por el Gobierno Nacional, y las últimas décadas del siglo XIX tuvieron en la casona a una sede del Correo en el edificio. A principios del siglo XX, el edificio es demolido y el lote subdividido (Lafuente Machain 1978), el de la esquina de Bolívar y Moreno, paso a ser propiedad de la familia Raggio, el antiguo colegio, actualmente es ocupado por un emprendimientogastronómico, y el que nos ocupa a nosotros vio levantarse un edificio que durante varias décadas fue utilizado como "inquilinato”, hasta su demolición en 1973.

\section{Objetivos}

Diagnosticada la relevancia del sitio, y una vez que la Gerencia Operativa de Patrimonio entró en conocimiento sobre la venta del lote correspondiente a Moreno 550, comenzó la intervención como órgano de aplicación de la Ley in situ, poniendo en conocimiento de los emprendedores sobre las facultades del organismo, y acerca del potencial arqueológico del mismo sitio.

Nuestro trabajo, busca describir a partir de esa primer intervención, todo el proceso de acciones que se fueron suscitando, desde la aparición de una estructura de proporciones únicas en la Ciudad, el diagnóstico que nospermitió definirla como una cisterna, los daños causados a la misma por la empresa constructora, hasta el arribo a un acuerdo entre el Gobierno de la Ciudad y los desarrolladores inmobiliarios, que culminó con un sistemático trabajo arqueológico y la proyección de un Museo de Sitio en el lugar.

Este detalle de acciones son abordadas desde las vivencias y experiencias por parte del equipo del CIAP que se vio envuelto en el mismo, y con el consentimiento de las autoridades de la Dirección General de Patrimonio, Museos y Casco Histórico.

\section{Metodología de intervención}

Las intervenciones en el sitio, fueron producto de los vaivenesproducidos a lo largo de los tres primeros meses, lo cual determinóque el estudio se desarrollara en diferentes momentos o etapas.

1. Etapa de reconocimiento: Guarda relación con los primeros momentos de intervención, en los cuales en pleno ejercicio de sus facultades, personal del órgano de aplicación de la ley 25.743, se hizo presente en el sitio con motivo de hacerle entrega a los emprendedores del mismo, de una nota oficial en la cual se dejaban asentadas nuestras funciones como veedores, poniéndolos en conocimiento sobre el potencial arqueológico del lugar, y que frente a cualquier tipo de irrupción de algún tipo de objeto, estructura o 
resto arqueológico o paleontológico, conforme a lo establecido en el Art. 13 de dicha ley sobre la obligación de denunciar los mismos ante la DGPMyCH.

Esta presentación, se llevó a cabo días antes que la propia maquinaria de una de las empresas a cargo de las obras, lograra descubrir la parte superior de una estructura, lo cual generó que se debiera con los responsables de la obra, su intervención inmediata para diagnosticar su naturaleza y relevancia arqueológica.

En relación a actuado y mencionado más arriba, el Decreto reglamentario de la Ley 25.743, 1022/04 da cuenta de los procedimientos a seguir tras algún tipo de hallazgo arqueológico y sobre

La obligación de denunciar el descubrimiento a que se refiere el artículo 13 de la ley implica la de suspender toda actividad en el lugar hasta tanto la autoridad competente, según la jurisdicción de que se trate, tome la intervención prevista legalmente, debiendo adoptarse, hasta entonces por responsables del predio, todas las medidas tendientes a la conservación del yacimiento y/o los objetos arqueológicos o paleontológicos. (Ley 25.743)

Los primeros trabajos realizados se llevaron a cabo conviniendo con los propietarios del inmueble las modalidades de la misma, conforme al Art $\mathrm{N}^{\circ} 35$ “Cuando los vestigios arqueológicos o paleontológicos se encuentren en terrenos de propiedad privada, la autoridad competente acordará con sus propietarios lo necesario para facilitar el estudio y/o preservación del yacimiento” (Ley 25.743. Art 13 Decreto reglamentario 1022-04). En consecuencia, se obtuvo de los emprendedores una plena libertad para desarrollar las tareas requeridas (Figura 3; 4 y 5)

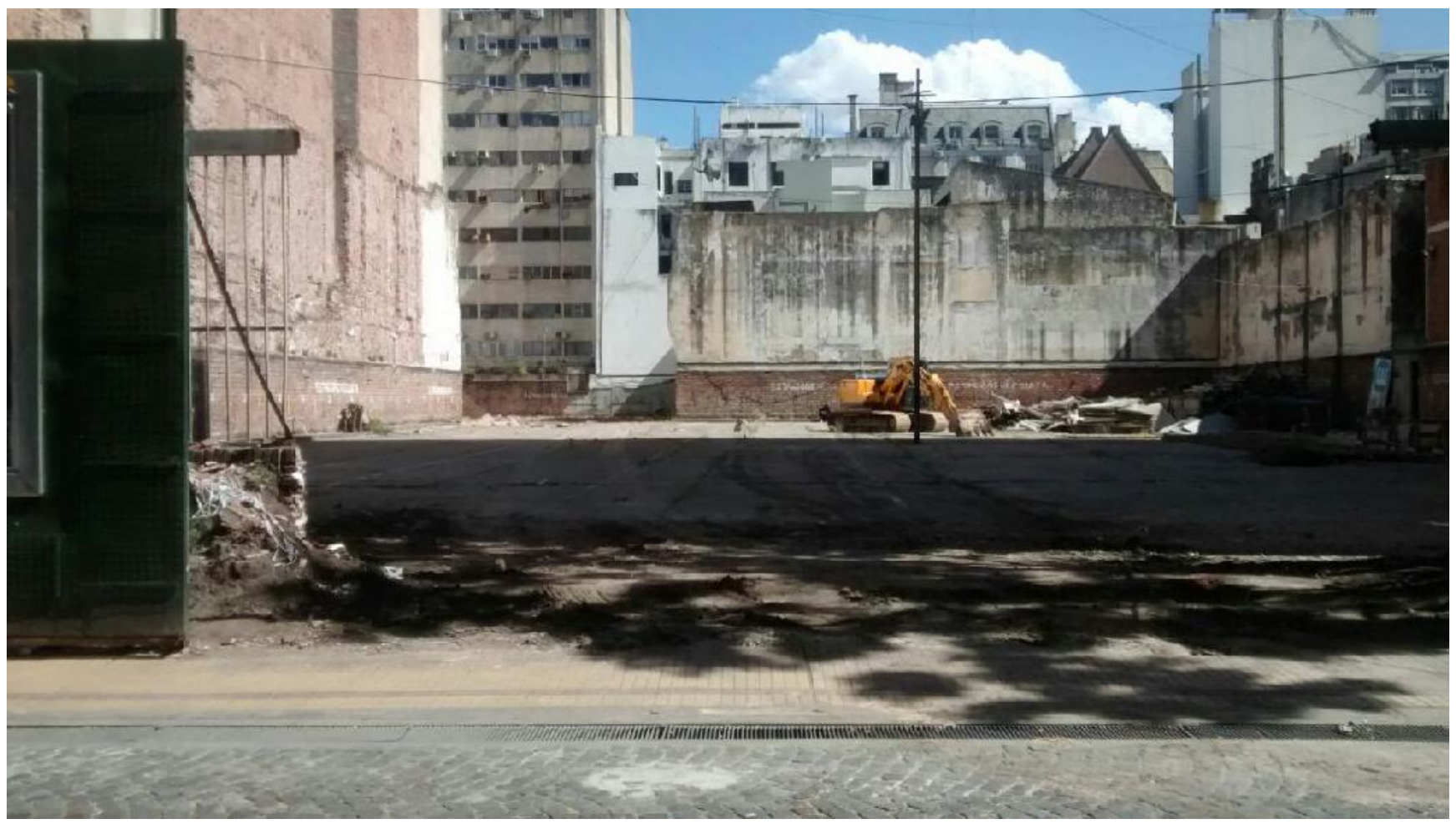

Figura 3. Momentos de la primer intervención previos a los inicios de la obra, el 21 de Noviembre de 2017 
Teoría y Práctica de la Arqueología Histórica Latinoamericana | Año VIII. Vol. 9 | 2019

ISSN en línea: 2591-2801 | ISSN versión impresa: 2250-866X

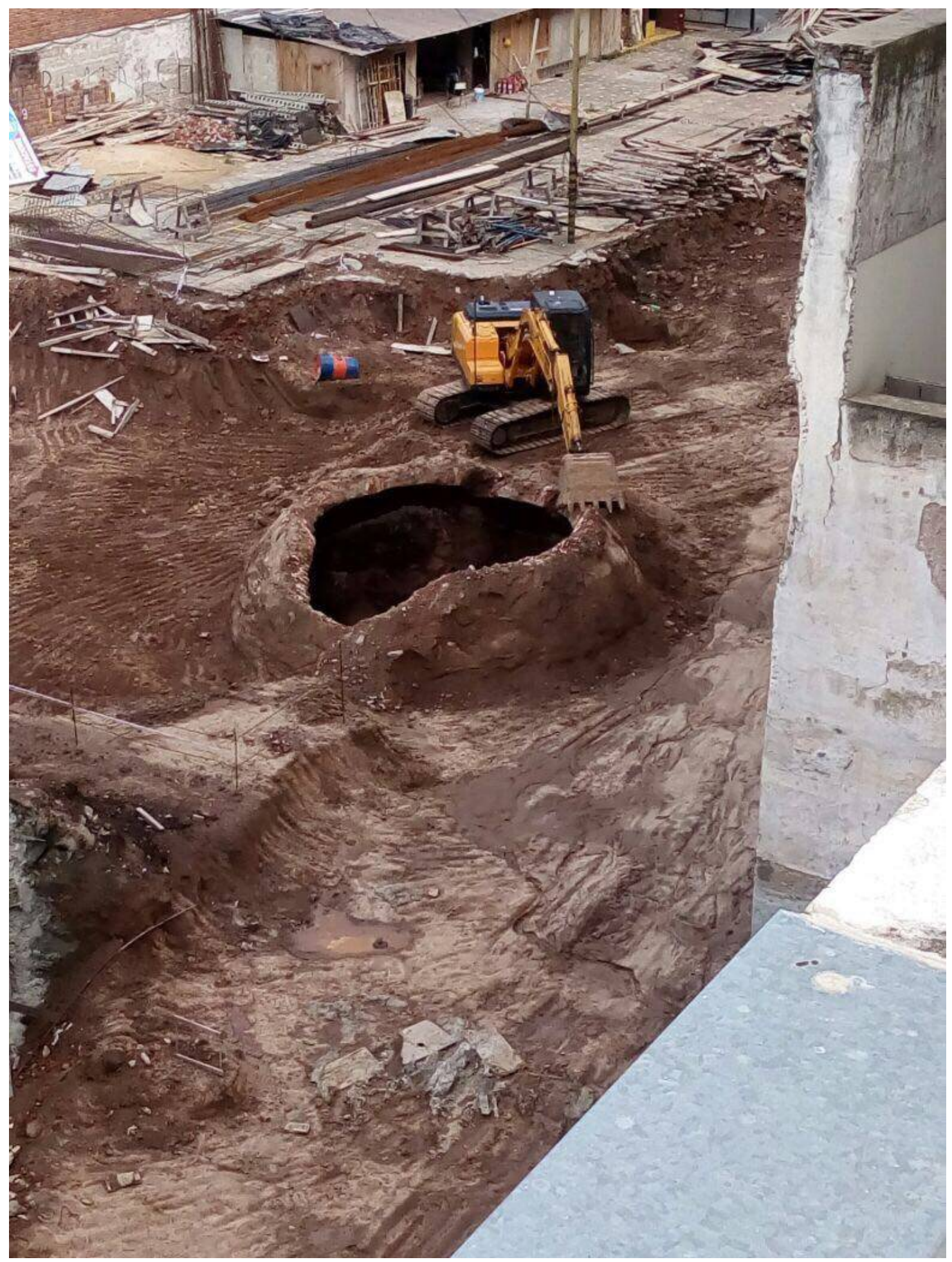

Figura 4. La cisterna poco tiempo antes de la demolición del domo. Imagen enviada a la DGPMyCH junto a la denuncia de un vecino el 18 de diciembre de 2017. 


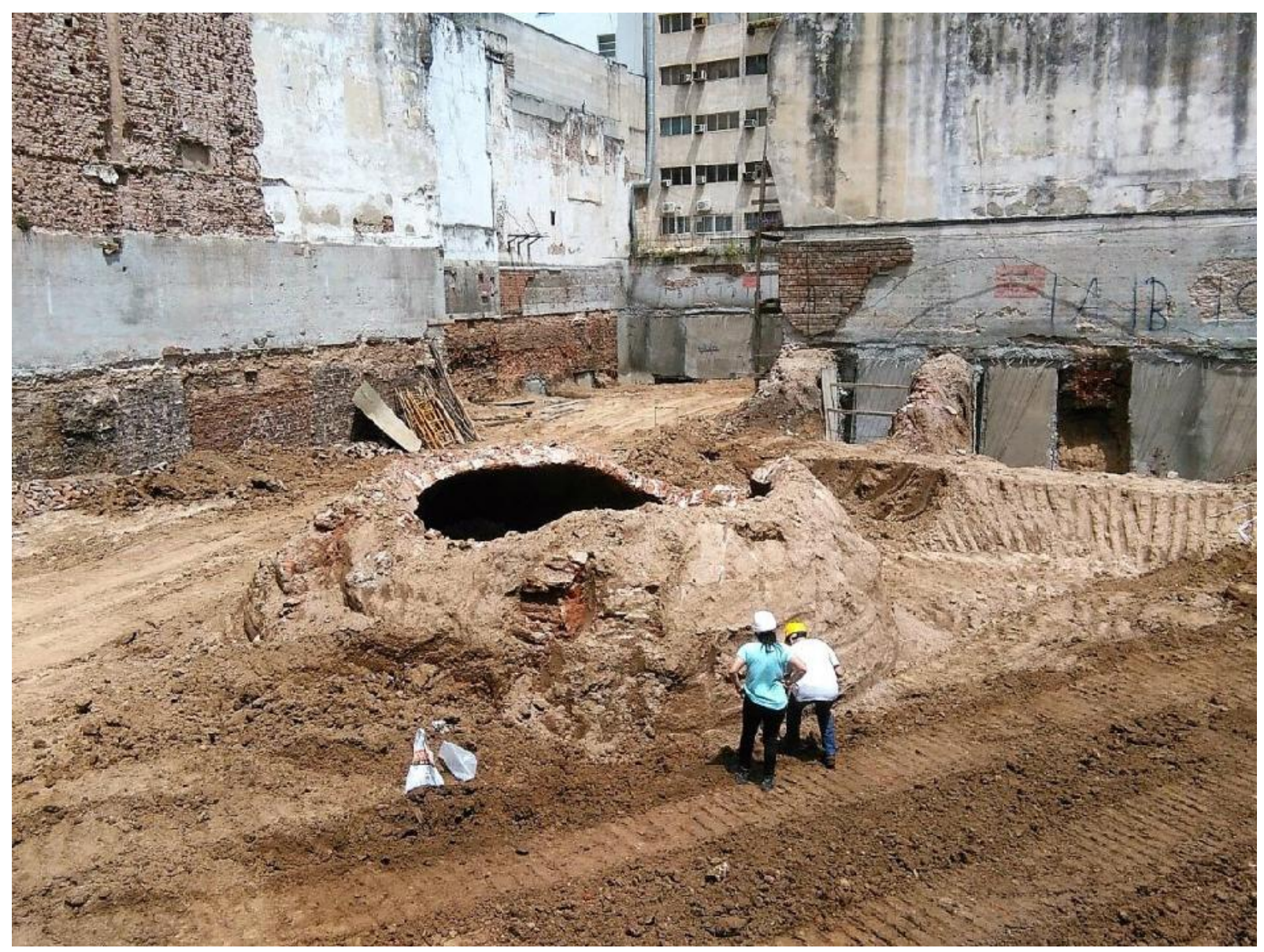

Figura 5. Personal de la DGPMyCH junto a la persona encargada de Higiene y Seguridad de la obra 27 de diciembre de 2017.

2. Etapa de diagnóstico: Tuvo que ver con un reconocimiento de estructuras del lugar, y en particular de aquella estructura abovedada que había emergido días antes. En consecuencia, se les comunica a los responsables de la obra sobre la importancia de estas acciones y se acuerda con ellos las modalidades de ingreso al predio. De esta manera, a partir del 22 de diciembre de 2017, personal del CIAP en conjunto con arquitectos de la DGPMyCH comienzan los estudios en el sitio, teniendo en cuenta la legislación vigente, que de acuerdo al artículo en su Decreto Reglamentario 1022-04, establece que

Si en el curso de ejecución de obras públicas o privadas, que implique movimientos de tierra, se hallaren fósiles u objetos arqueológicos, o se supiera que determinados sectores, regiones o zonas, constituyen yacimientos paleontológicos y/o arqueológicos, que por su tamaño, valoración patrimonial, científica y/o estado de preservación requieran especial cuidado, protección absoluta o parcial, trabajos de rescate o preservación, la autoridad de aplicación jurisdiccional podrá solicitar la intervención del Poder Ejecutivo Nacional, a fin de adoptar medidas tendientes a lograr la suspensión de las obras o proyectos en forma definitiva o temporal, según el caso. (Ley 25.743. Art 13 Decreto reglamentario 1022-04) 
Los resultados de esta aproximación, tuvo que ver con identificar la naturaleza de las estructuras, las cuales indicaron que aquella estructura de ladrillos descubierta, obedecía a una cisterna de siete metros de diámetro, una de las de mayores dimensiones halladas hasta la fecha en la Ciudad y comparable a las de la Imprenta Coni (Perú 680), Bolívar 466, y la propia de los Altos de Elorriaga (Alsina 417). Por otro lado, se pudo visualizar restos de cimientos y fragmentos de pisos y tejas coloniales, resultado de la demolición de los edificios preexistentes, algunos de ellos correspondientes al de la antigua casa de los Ezcurra, y posteriores usos, demolidos durante la primera década del siglo XX, pozos de descartes con una amplitud cronológica que van desde el siglo XVII al XIX, y variados fragmentos de objetos dispersos a lo largo de todo el terreno.

Los aljibes con cisternas, eran estructuras de uso doméstico, complejas y costosas en relación a otro tipo de pozos, y no muchas familias disponían de los recursos monetarios para poder contar con una de ellas. El sistema consistía en una cámara bajo tierra, cubierta en su parte superior por una bóveda que podía ser redondeada o cuadrangular, los pisos de baldosas, y las paredes cementadas o encaladas impermeables. El ingreso de agua se producía a través de albañales o caños de hierro desde las terrazas o patios, por arriba o por el costado, para terminar recogiéndose desde un brocal a través de un balde. En la parte central del piso, se ubicaba un pozo de decantación redondo hacia donde mediante un leve desnivel del suelo escurría sus aguas. Las dimensiones de estas estructuras son muy variadas, entre uno a siete metros de ancho, y cinco a siete metros de profundidad (Schávelzon 2018). Era una alternativa más onerosa, al consumo de agua provista por los aguateros, los cuales muchas veces suministraban el tan preciado recurso con sedimento o tierra (Figura 6 y 7).

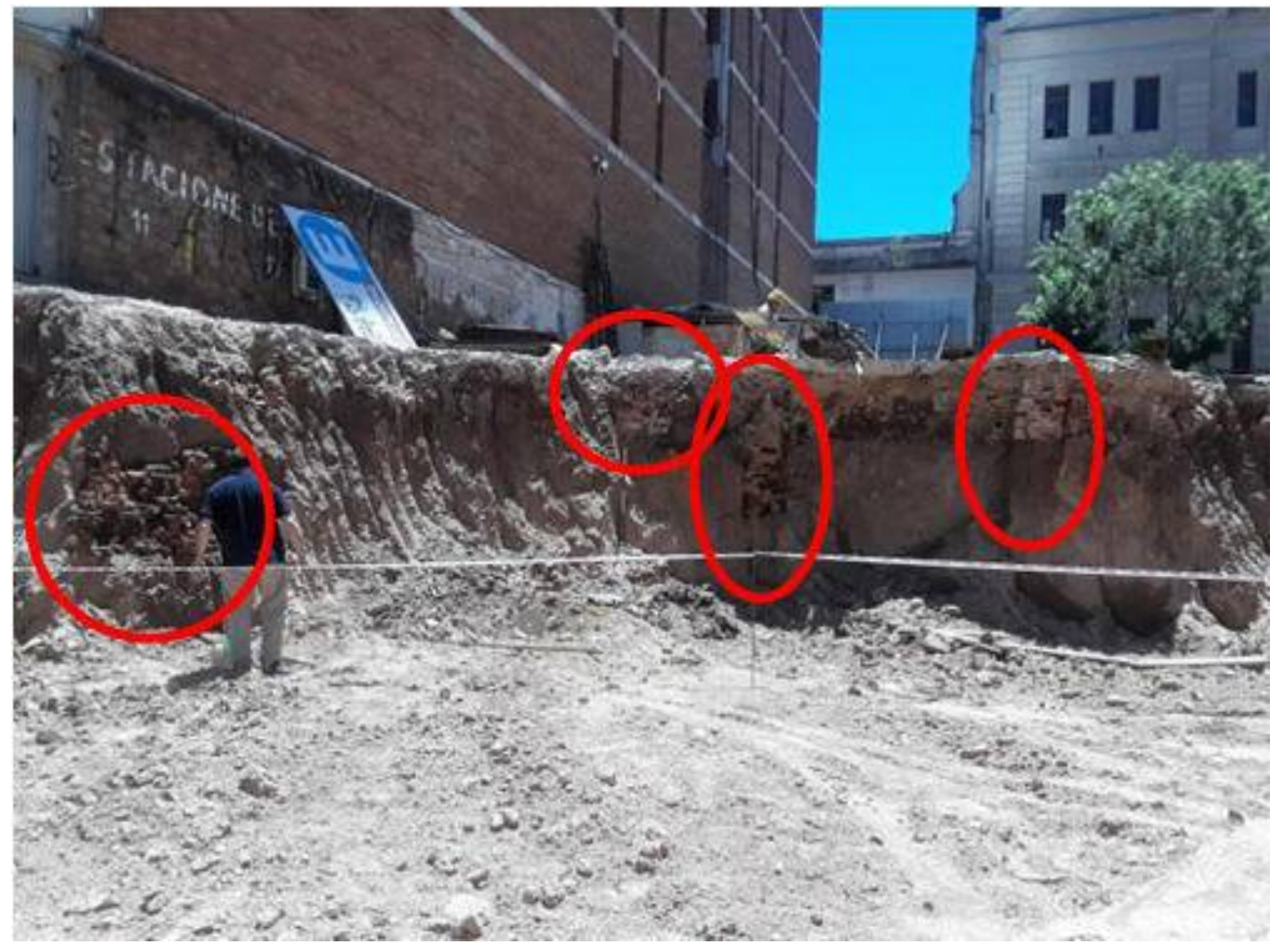

Figura 6. Vista de cimientos correspondientes a los siglos XVIII y XIX que emergieron bajo la superficie de la antigua playa de estacionamiento Foto (CIAP-DGPMyCH) 


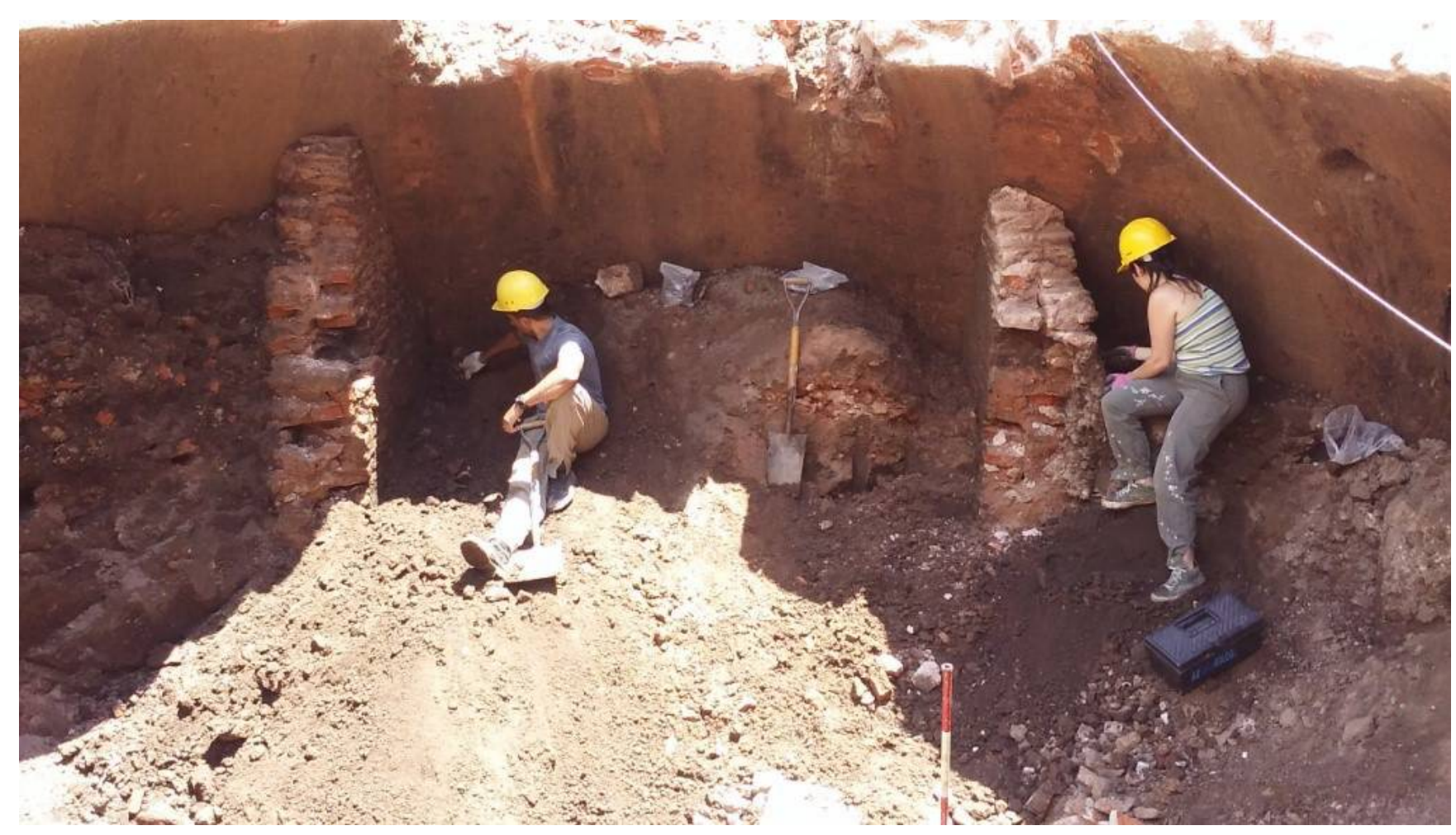

Figura 7. Personal del CIAP en instancias del relevamiento dentro de la cisterna Foto (CIAP-DGPMyCH)

El relevamiento llevado a cabo en la cisterna, solo una semana sobre la misma, se logró rescatar un centenar de objetos y restos que permitieron establecer una cronología variable producto del relleno sufrido por esta estructura en su interior. Entre el registro de material recuperado, se pueden citar; cerámicas de tradición hispano indígenas con uso de torno, mayólicas esmaltadas sevillanas propias del siglo XVIII, de Triana policromas de principios del XIX y azulejos del siglo XVIII. Finalmente, se rescataron cerámicas de manufactura local, de vidriado verde que debieron haber sido producto del relleno del pozo, posterior a la entrada en desuso del mismo. (Informe DGPMyCH, 2018)

Como órgano de aplicación, desde el momento en que el yacimiento fue reconocido como tal, se comenzaron las tareas de supervisión del mismoen que consistieron estas tareas:

Los vestigios arqueológicos y restos paleontológicos inmuebles registrados que se encuentren dentro de predios de propiedad particular quedan sujetos a la vigilancia permanente del organismo competente quien podrá inspeccionarlos siempre que lo juzgue conveniente, no pudiendo los propietarios o responsables crear obstáculos a la simple inspección. (Ley 25.743. Artículo 15)

3. Etapa de destrucción del “domo” de la cisterna. La etapa anterior había sido contemplada hasta el día 5 de enero de 2018, tras lo cual se elaboraría el informe técnico correspondiente a las observaciones realizadas. Sin embargo, el día 27 de diciembre, la superficie visible de la cisterna (Figura 8 y 9) fue destruida lo cual significó que la DGPMyCH, como órgano de aplicación de la ley, debieraaccionar en contra de los responsables, recordando que el Art $\mathrm{N}^{\circ} 13$ menciona que 
Toda persona física o jurídica que practicase excavaciones con el objeto de efectuar trabajos de construcción, agrícolas, industriales u otros de índole semejante, está obligado a denunciar al organismo competente el descubrimiento del yacimiento y de cualquier objeto arqueológico o resto paleontológico que se encontrare en las excavaciones, siendo responsable de su conservación hasta que el organismo competente tome intervención y se haga cargo de los mismos (Art $\mathrm{N}^{\circ} 13$ )" y "La obligación de denunciar el descubrimiento a que se refiere el artículo 13 de la ley implica la de suspender toda actividad en el lugar hasta tanto la autoridad competente, según la jurisdicción de que se trate, tome la intervención prevista legalmente, debiendo adoptarse, hasta entonces por responsables del predio, todas las medidas tendientes a la conservación del yacimiento y/o los objetos arqueológicos o paleontológicos (Art Nº 13 Decreto reglamentario 1022-04).
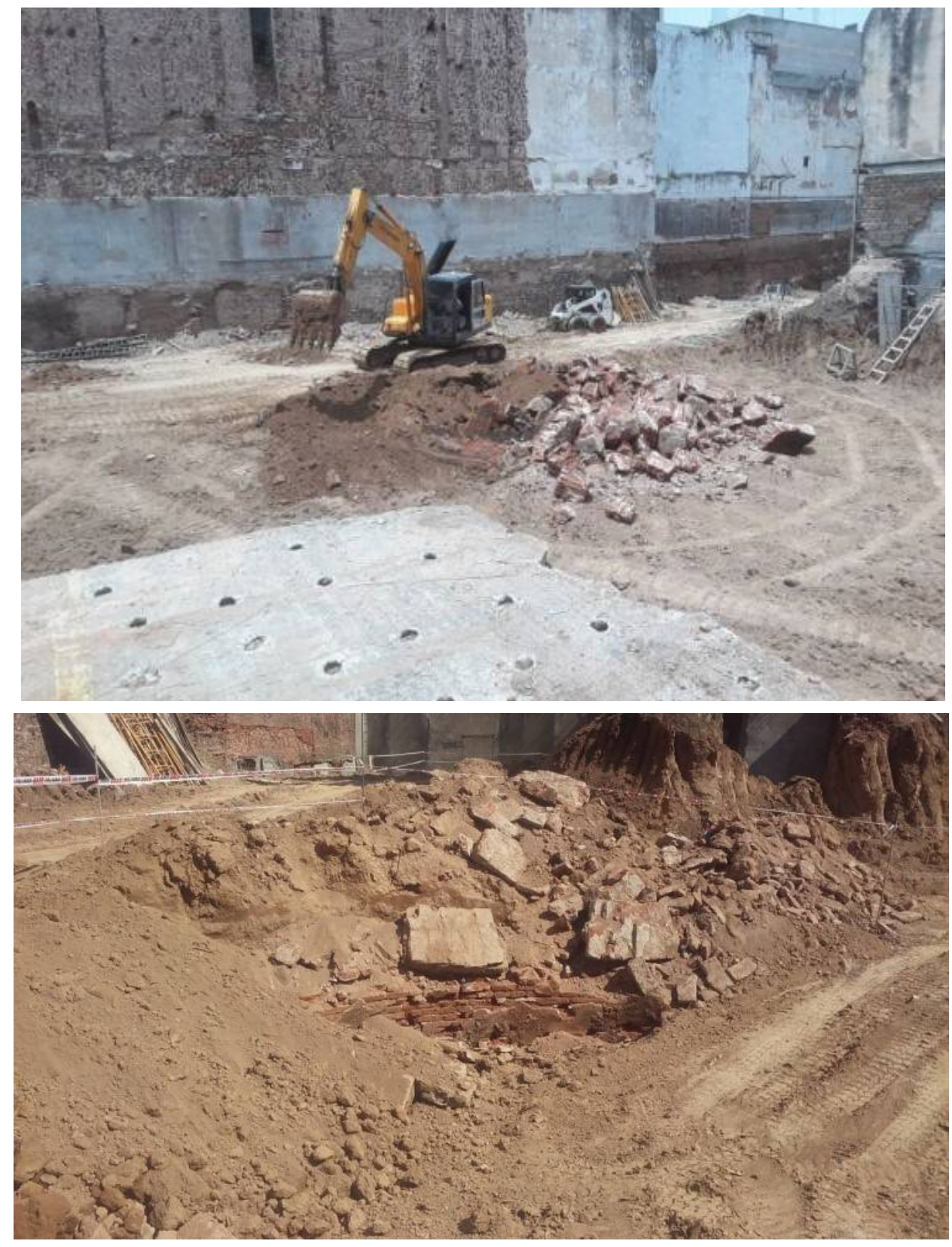

Figuras 8 y 9. Restos de la cisterna tras los daños recibidos en la parte del "domo" de la misma. Se aprecian restos de sus paredes, relleno y revoque (Foto CIAP-DGPMyCH) 
Teoría y Práctica de la Arqueología Histórica Latinoamericana | Año VIII. Vol. 9 | 2019

ISSN en línea: 2591-2801 | ISSN versión impresa: 2250-866X

Si bien, la DGPMyCH accionó de oficio tras del hallazgo de la cisterna, los propietarios del predio, tal cual lo exige la ley en su Art. $N^{\circ} 11$, debieron haber llevado a cabo la denuncia correspondiente. "Los dueños de los predios en que se encuentren yacimientos arqueológicos o paleontológicos, así como toda persona que los ubicare, deberá denunciarlos ante el organismo competente a los efectos de su inscripción en el registro correspondiente” (Ley 25.743. Artículo 11).

4. Implicancias judiciales. Acuerdo de intervención arqueológica, protección de la cisterna y construcción de "Museo de Sitio". Las implicancias de la destrucción de la estructura, significó que el Gobierno de la Ciudad de Buenos Aires interviniera a través de la DGPMyCH, quien denunció judicialmente el incumplimiento a la ley de protección del Patrimonio Arqueológico y Paleontológico, y lo pactado entre las partes en las etapas antes descriptas,lo que significó la paralización de las obras en el sitio, laintervención de la Dirección General de Fiscalización y Control de Obras (DGFyCO), dependiente de la Agencia Gubernamental de Control, y las Direcciones de Emergencias y la Guardia de Auxilio, vinculado con los posibles riesgos de colapso y necesidad de apuntalamiento en las medianeras. En consecuencia, se debe considerar que ante cualquier tipo de transgresión a la ley, el Art $\mathrm{N}^{\circ} 38$, establece que las penalidades son:

a) Apercibimiento.

b) Multa: Esta será establecida entre un mínimo de diez por ciento (10\%) hasta tres veces el valor del bien o los bienes que hayan motivado la conducta sancionada. El Poder Ejecutivo nacional establecerá en la reglamentación de la presente ley una multa dineraria para los casos donde la determinación del valor del bien sea imposible o dificultosa. Para la determinación de lamulta se atenderá a la gravedad de la falta cometida y al carácter de reincidente del infractor.

c) Decomiso de los materiales arqueológicos, paleontológicos y/o de los instrumentos utilizados para cometer la infracción. d) Suspensión o caducidad de la concesión.

e) Inhabilitación.

f) Clausura temporaria o definitiva. (Ley 25.743, Artículo 38)

Mientras que en su Decreto Reglamentario, se determina que

Para la aplicación de la multa del inciso b) del artículo 38 de la Ley, cuando la determinación del valor del bien sea imposible o dificultosa, se impondrá una multa que podrá variar en su monto a un equivalente de entre DIEZ (10) y CIEN (100) salarios mínimos, de acuerdo a la gravedad del hecho y será fijada por la autoridad de aplicación correspondiente jurisdicción. (Ley 25.743)

Judicialmente, interviene el Juzgado Penal y Contravencional de faltas $N^{\circ} 2$, la Fiscalía de $N^{\circ} 1$, y de la Unidad Fiscal especializada en materia ambiental de la Fiscalía de la Ciudad, a cargo del Dr. Matías Michienzi. Es en esta instancia en la cual, el juzgadointerviniente solicita a la DGPMyCH, que haga presentación de un Plan de Acción Arqueológica a implementar en el sitio, lo cual significó que se determinara:

1.- Aplicación detécnicas arqueológicas de excavación en el interior de la cisterna tendiente a recuperar información de relevancia para su posterior investigación.

2.- Relevamiento de cimientos de la totalidad del predio e intervención de todas aquellas estructuras detectadas durante el avance de las obras.

3.- Restauración de cisterna a partir de informe técnico elaborado por un experto en materia de restauración. 
Teoría y Práctica de la Arqueología Histórica Latinoamericana | Año VIII. Vol. 9 | 2019

ISSN en línea: 2591-2801 | ISSN versión impresa: 2250-866X

Para cumplimentar estas tareas, se propone que los propietarios del sitio contraten a un equipo arqueológico, especializado en tareas de esta índole. Este punto, es establecido ya en la ley

Las personas físicas o jurídicas, responsables de emprendimientos deberán prever la necesidad de realizar una prospección previa a la iniciación de las obras con el fin de detectar eventuales restos, yacimientos u objetos arqueológicos o paleontológicos. De verificarse su existencia, deberán facilitar el rescate de los mismos. Las tareas que se realicen a ese efecto deberán ser aprobadas por la autoridad de aplicación jurisdiccional. (Art 13 Decreto Reglamentario 1022-04)

Por otro lado, se sugiere la participación de un especialista en patrimonio encargado de la restauración de la cisterna, cuya modalidad queda en manos de la Gerencia Operativa.

4.- Sondeos en los muros de la cisterna a modo de poder determinar fehacientemente la profundidad de la misma.

5.- La Gerencia Operativa actuará como contralor y supervisor de las tareas que se practiquen en el sitio conforme a lo establecido por la ley

La autoridad competente podrá designar veedores a fin de ejercer el control de las investigaciones y asegurar la realización sistemática de las tareas correspondientes, debiendo los responsables de las misiones científicas suministrarles toda la información que les sea requerida en cumplimiento de la presente ley. (Art $N^{\circ} 32$ )

Se debe destacar, que el material de origen arqueológico que fuese recuperado durante las intervenciones aplicadas en el sitio,

son del dominio público del Estado nacional, provincial o municipal, según el ámbito territorial en que se encuentren” (Art N9), “los materiales arqueológicos y paleontológicos procedentes de excavaciones realizadas mediante concesiones o resultantes de decomisos pasarán a poder del Estado nacional, provincial o municipal, según correspondiere, quedando los organismos de aplicación facultados a darle el destino que consideren más adecuado y a fijar los espacios que reúnan los requisitos de organización y seguridad indispensables para su preservación. (Art N 10)

\section{Mientras que}

Los vestigios arqueológicos y restos paleontológicos inmuebles registrados que se encuentren dentro de predios de propiedad particular quedan sujetos a la vigilancia permanente del organismo competente quien podrá inspeccionarlos siempre que lo juzgue conveniente, no pudiendo los propietarios o responsables crear obstáculos a la simple inspección. (Art Nº15)

Los objetos de procedencia arqueológica -como se mencionó-, son de propiedad del Estado nacional, provincial o municipal, según corresponda.Cuando se aprueba un proyecto de excavación, el órgano de aplicación establece marcos temporales que incluyan no solo los tiempos solicitados de intervención, sino también un plazo prudente, en el cual los profesionales a cargo del proyecto, puedan llevar a cabo las correspondientes tareas de análisis y laboratorio, elaboración de informes y finalmente, el registro de objetos y restos. Cumplimentado este proceso, los investigadores deben hacer entrega de la colección al órgano de aplicación correspondiente. No obstante, es frecuente que objetos rescatados durante trabajos arqueológicos, puedan ser finalmente exhibidos en el sitio en cuestión, como ocurrirá con el Proyecto Moreno 550, y tal cual ocurrió con otros tantos como el Ex Pasaje Belgrano, la Pulpería Quilapán, el Zanjón de Granados,la Tasca de los Cuchilleros, Santa Catalina, entre otros. 
Frente a lo presentado por la Gerencia Operativa de Patrimonio- DGPMyCH ante la justicia, el Estudio Kohon, responsable del emprendimiento contrató al Arq. MedericoFaivre, especialista en patrimonio, con la finalidad de tener bajo su responsabilidadel equipo encargado de realizar las excavaciones arqueológicos en el lugar ytodas las acciones llevadas a cabo en el sitio tendientes a proteger y revalorizar el patrimonio subyacente. A su vez, el equipo a su cargo junto al propietario del predio, en muestra de buena voluntad, y tendiente a aminorar las penalidades judiciales que pudieran recaer sobre los responsables de los daños ocasionados, presentaron un Proyecto de Museo de Sitio, en torno a una protegida cisterna. Todas estas tareas quedaron bajo la supervisión y aprobación de la Gerencia Operativa de PatrimonioDGPMyCH.

El Proyecto "Museo de sitio", fue pensado como un emprendimiento construido para proteger a la cisterna y estructurar en torno a ella una sala de muestras y exhibiciones permanentes o periódicas, que estarán a cargo de la DGPMyCH.

\section{Proyecto Museo de Sitio presentado por el estudio Kohon}

El concepto de Museo de Sitio es situarse en el preciso lugar donde determinados hechos se han desarrollado, permitiendo conocerlos, interpretarlos y difundirlos. En el año 1982, el ICOM publica un informe sobre museos de sitio, los cuales son concebidos para proteger y conservar el patrimonio natural y cultural, mueble e inmueble en su lugar de origen (Faivre, et al. 2018) (Figura 10).

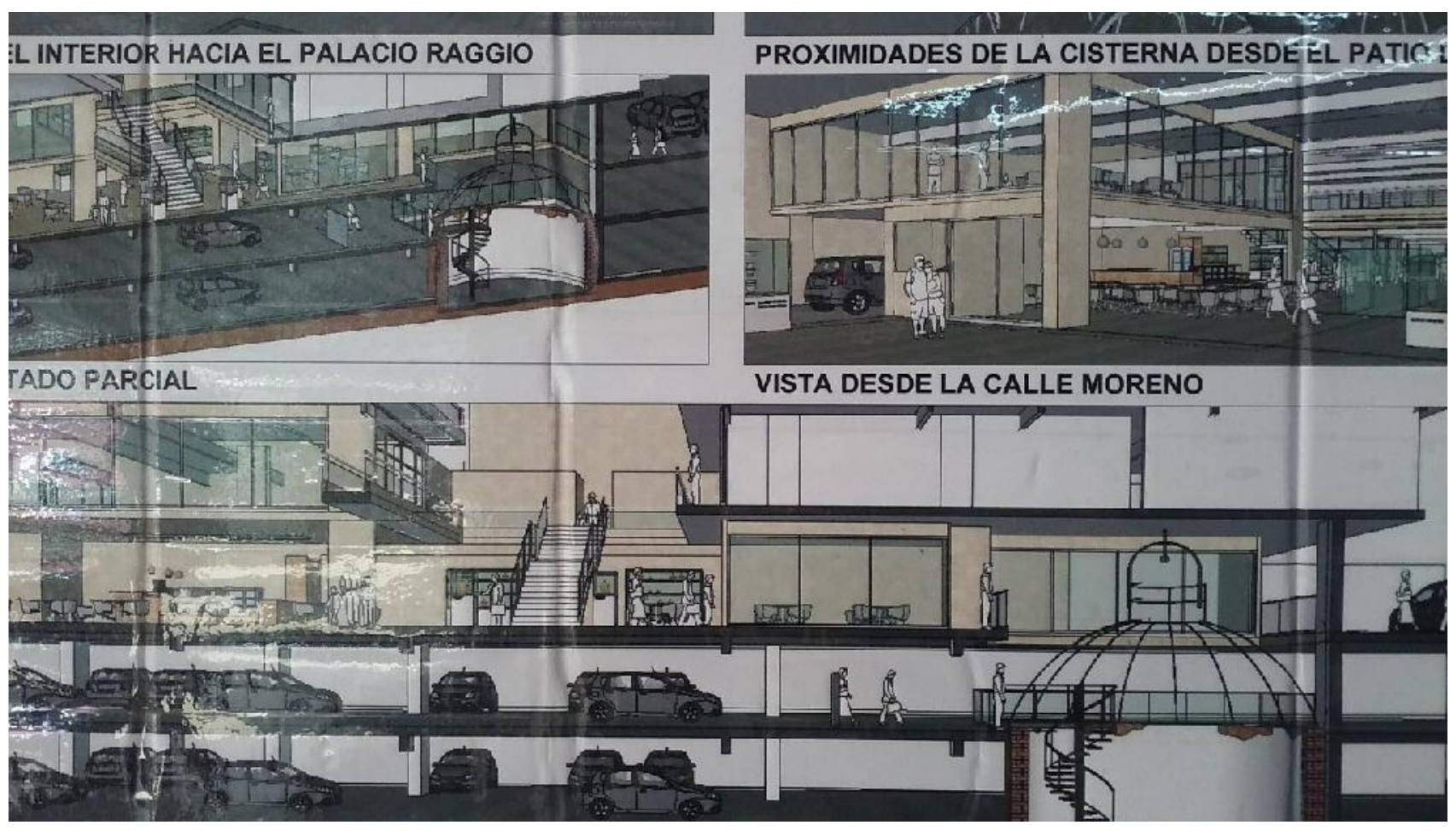

Figura 10. Imágenes del proyecto “Museo de Sitio” Moreno 550 presentado por el estudio Kohon, sobre Proyecto de Museo de Sitio elaborado por el estudio Faivre y asesoramiento de Jorge Tartarini 
El proyecto contempla tres aspectos fundamentales: la investigación histórica documental de base que permitirán diseñar la propuesta museográfica, los resultados de los trabajos arqueológicos emprendidos en el sitioy la adaptación delpro a la idea original el predio(Faivre et al. 2018)

La cisterna, ubicada en la Planta Baja del edificio proyectado, será puesta en valor aplicando trabajos de restauración y protección, generando un entorno de diversas actividades asociadas a la historia el sitio y al barrio que forma parte. El contexto estará dominado por diferentes emprendimientos gastronómicos, culturales y sociales como un continum del espacio público sobre la calle Moreno.(Faivre et al. 2018)

El estudio Faivre sostiene que el Museo de Sitio, estará compuesto por un salón de 17,50 m por 4,00 y 3,00 m de altura, dotado de un "muro exhibidor" de $50 \mathrm{~m} 2$ que permitirá la visualización de colecciones diversas. Adjunta a esta sala, habrá una oficina auxiliar de 7,20 m2. La cisterna contará a su vez con un entrepiso vidriado que permitirá aproximarse a su interior y apreciarla desde su parte superior.

Todo el conjunto conforma un ámbito de $187 \mathrm{~m} 2$ de superficie, el cual sumado al entrepiso de $47 \mathrm{~m} 2$, dan forma a una superficie de $34 \mathrm{~m} 2$ en planta. Finalmente, se contará con un auditorio externo para usos eventuales y capacidad para entre 70 y 100 personas.

\section{Consideraciones finales}

El Sitio Moreno 550, marcó un hito desde la función pública, un ejemplo único en el distrito, en el cual la aplicación de la ley significó, ante el daño ocasionado en el patrimonio arqueológico por parte de los responsables inmobiliarios en el lugar, la parálisis de la obra en cuestión y el arribo entre las partes a un acuerdo que en adelante beneficiará a todos los vecinos y paseantes. Esta experiencia, pone de manifiesto como anteacciones nocivas para el Patrimonio, éstas pueden revertirse y culminar en situaciones altamente positivas para los ciudadanos que disfrutarán el bien patrimonial.

Moreno 550, significa otro ejemplo de cómo lo arqueológico y lo urbano pueden complementarse, y en este sitio en particular, dada la proximidad y apreciable ubicación dentro del Casco Histórico. El "Museo de Sitio" quedará como un referente en lo arqueológico destinado al público en general y será la primera experiencia de este tipo en el ámbito delGobierno de la Ciudad de Buenos Aires, complementándose la cisterna con salas de exhibiciones, conferencias y eventos.

Las derivaciones delcaso del Sitio en Moreno 550 con el futuro Museo de Sitio incluido, es un logro que se vislumbra en medio del trabajo de concientización sobre el patrimonio realizado por el Centro de Interpretación de Arqueología y Paleontología en múltiples ocasiones (talleres para niños, charlas de divulgación, La Semana de la Arqueología, etc.).

\section{Referencias bibliográficas}

BEARE, P. (1860 a 1870) Catastro Beare, compuesto de 14 parroquias de la ciudad de Buenos Aires.

Decreto Reglamentario 2022/04(2004) Ley 25.743 de Protección del Patrimonio Arqueológico y Paleontológico. Recuperado de http://servicios.infoleg.gob.ar/infolegInternet/anexos/85000-89999/86356/ norma.htm

Dirección General de Patrimonio y Casco Histórico (2018) Informe Arqueológico sobre el lote ubicado en Moreno 550.

Estudio Arq. Mederico y Pablo Favre, asesoramiento Jorge Tartarini (2018). Proyecto Museo de Sitio Moreno 550. Argentina: Buenos Aires 
Disposición $N^{\circ} 2$ DGPAT, publicado en el Boletín oficial $N^{\circ} 2377$, el 2 de febrero de 2006 de creación del Registro de Yacimientos, Colecciones, Lotes y Objetos Arqueológicos, de Restos fósiles, Colecciones y Yacimientos Paleontológicos; y de Infracciones y Reincidentes.

Estudio Arq. Pablo y Mederico Faivre conasesoramiento de Jorge Tartarini (2018). Informe Histórico de apoyo al proyecto de un Museo de Sitio. Argentina: Buenos Aires

LAFUENTE MACHAIN, R. (1978). El Barrio de Santo Domingo. Cuadernos de Buenos Aires.

LEY 25.743 (2003) Protección del Patrimonio arqueológico y Paleontológico ene l territorio Nacional. Recuperado de http://servicios.infoleg.gob.ar/infolegInternet/anexos/85000-89999/86356/norma. $\underline{\mathrm{htm}}$

RAVIGNANI, E. (1919). Territorio y población: padrón de la compaña de Buenos Aires (1778). Padrones complementarios de la ciudad de Buenos Aires (1806, 1807, 1809 y 1810). Censo de la ciudad y compaña de Montevideo (1780). Buenos Aires: Compañia sud-americana de billetes de banco.

SCHÁVELZON, D. (2018). Manual de arqueología urbana. Técnicas para excavar Buenos Aires” Buenos Aires: Centro de Arqueología Urbana.

SERÓ MANTERO, G. (2000) La casa de María Josefa Ezcurra. Una de las viviendas más antiguas de Buenos Aires. Buenos Aires: Gobierno de la Ciudad de Buenos Aires

TAULlARD, A. (1940) Los planos más antiguos de Buenos Aires: 1580-188. Buenos Aires: Jacobo Peuser

Recibido: 26 de junio de 2019

Aceptado: 24 de octubre de 2019 